\title{
Novel endoscopic therapeutic modalities for superficial neoplasms arising in Barrett's esophagus: a primer for surgical pathologists
}

\author{
Gregory Y Lauwers ${ }^{1}$, David G Forcione ${ }^{2}$, Norman S Nishioka ${ }^{2}$, Vikram Deshpande ${ }^{1}$, \\ Mikhail Y Lisovsky ${ }^{1}$, William R Brugge ${ }^{2}$ and Mari Mino-Kenudson ${ }^{1}$ \\ ${ }^{1}$ Gastrointestinal Pathology Unit, Department of Pathology, Massachusetts General Hospital and Harvard \\ Medical School, Boston, MA, USA and ${ }^{2}$ Division of Gastroenterology, Department of Medicine, \\ Massachusetts General Hospital and Harvard Medical School, Boston, MA, USA
}

\begin{abstract}
This review introduces some of the novel endoscopic modalities used for the treatment of superficial neoplasms arising in the setting of Barrett's esophagus, namely endoscopic mucosal resection and photodynamic therapy. We describe the appropriate technical details for pathologists to know to effectively communicate with the gastroenterologists as well as the pitfalls in the evaluation of endoscopic mucosal resection specimens and post photodynamic therapy follow-up biopsies.

Modern Pathology (2009) 22, 489-498; doi:10.1038/modpathol.2009.4; published online 13 March 2009
\end{abstract}

Keywords: Barrett's esophagus; high-grade dysplasia; intramucosal adenocarcinoma; endoscopic therapy

For the past 20 years, surgical resection has been the conventional therapy for not only invasive esophageal adenocarcinoma, but also for high-grade dysplasia (HGD) and intramucosal adenocarcinoma occurring within Barrett's esophagus. ${ }^{1}$ Although curative for most patients, esophagectomy is also associated with significant morbidity and mortality, ranging from 2 to $7 \%$ in centers with significant experience and up to $20 \%$ in hospitals, in which the procedure is carried out infrequently. ${ }^{2,3}$ Comorbid illnesses may also preclude surgery, particularly among older patients. In response to these limitations, novel mucosal ablative techniques have emerged steadily, with the goal of achieving a cure for early-stage neoplasms with either no risk or a low probability of lymph node metastasis, while avoiding the risks associated with surgery. ${ }^{4-6}$ Given their increasing popularity, it is important for pathologists to become acquainted with these modalities for working in unison with gastroenterologists. Among the various novel endoluminal therapies, photodynamic therapy (PDT), laser therapy, and endoscopic mucosal resection (EMR) have shown growing promise. ${ }^{7-10}$ Herein, we will discuss these new therapeutic modalities, focusing on those for which the pathologist's input is important.

Correspondence: Dr GY Lauwers, MD, Department of Pathology, Massachusetts General Hospital, 55 Fruit Street, WRN 2, Boston, MA 02114 USA.

E-mail: glauwers@partners.org

Received 12 September 2008; revised 24 September 2008; accepted 2 January 2009; published online 13 March 2009

\section{Endoscopic mucosal resection}

In contrast to laser and PDT (see below), which aim to destroy the neoplastic tissue in situ, EMR is a minimally invasive procedure that removes the neoplastic mucosa by resecting through the middle or deeper part of the submucosa (Figure 1). It enables microscopic examination for histologic confirmation of the grade and depth of invasion. Popularized in Japan, where it is used extensively for the resection of early gastric adenocarcinomas and for esophageal squamous cell carcinoma, EMR is being evaluated in the West for the treatment of early esophageal neoplasms arising in Barrett's esophagus..$^{9,11,12}$

The most common indication include well to moderately differentiated mucosal adenocarcinomas without angiolymphatic invasion or ulcer on endoscopy, and measuring $<2 \mathrm{~cm}$ in diameter. ${ }^{13}$

There are many technical variations of EMR. Currently, cap-assisted EMR is used widely for several purposes, including resection with curative intent of HGD-intramucosal carcinoma, as well as for diagnostic and staging purposes. (Figure 2) Its success lies in its remarkable safety when used in controlled settings.

\section{Pathologic Evaluation of EMR}

EMRs ought to be handled as surgical specimens. Thus, reporting of margins and depth of invasion is essential, as additional therapeutic options, includ- 


\section{Principle of Endoscopic Mucosal Resection}

a

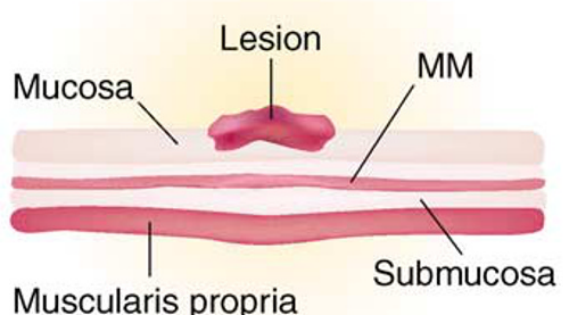

b

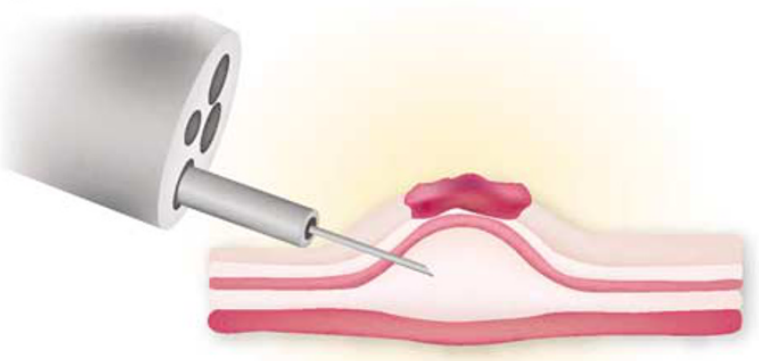

C

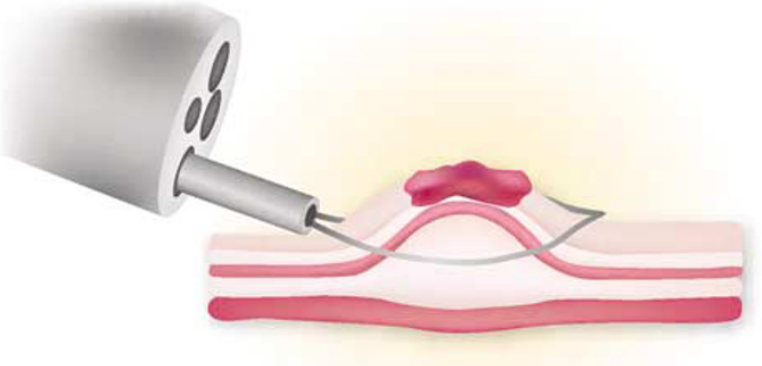

d

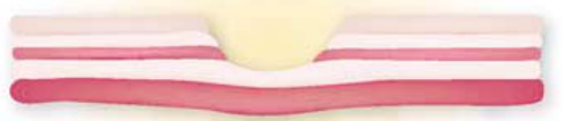

Figure 1 Principle of mucosal resection. (a) The anatomy of the esophageal wall. MM indicates muscularis mucosa. (b) The endoscopist first lifts the mucosal lesion from the submucosa by injecting saline into the submucosa, forming a bulla that will allow the safe removal of the lesion (c) without undue risk of perforation. (d) After resection the remaining mucosal and superficial submucosal ulceration will heal rapidly.

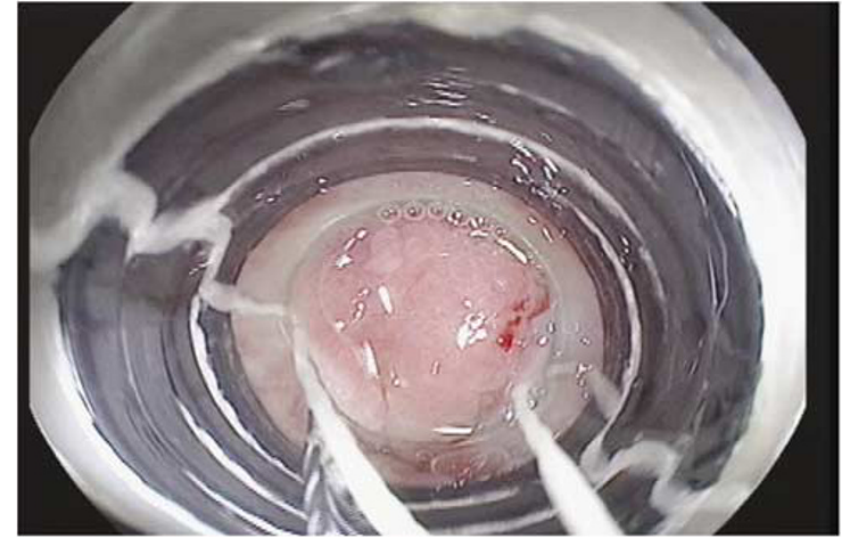

Figure 2 Endoscopic picture showing the lesion being lifted up through the cap.

ing repeat of EMR, PDT, or recourse to surgery, may be decided on pathologic evaluation.

Practically, before fixation, the EMR specimens should be mounted on a firm surface (eg, a wax block) and stretched gently. This step avoids curling of the specimens' edges and allows better slicing. Overstretching should be avoided, as it may lead to distortion and fracture of the tissue. Obtaining a picture of the specimen is a good practice, particularly when fragmented specimens have been submitted. It may indeed facilitate the visual reconstruction of the specimen and comparison with the endoscopic photographs. It may also be helpful for correlating unexpected findings, such as a positive margin, with the gross appearance of the lesions. Inking of the deep and circumferential margins is useful, when assessing the overall completeness of the resection. After fixation (optimally for no $<2 \mathrm{~h}$ ), serial sectioning of the EMRs at 2-mm intervals is carried out. (Figures 3 and 4) If applicable, additional radial sections should be made at both ends of the specimen to further evaluate the status of the circumferential margin. If the specimen is small, both ends need to be submitted en face. Piecemeal EMRs are usually difficult to stage. The fragments may be too small for stretching, and attempts to reconstruct the specimens may be challenging. In such circumstances, a direct communication with the gastroenterologist is important. In our own experience, $26 \%$ of the EMRs were fragmented. ${ }^{14}$ This problem is in fact more common with the newly introduced band ligation technique, which allows resection of larger lesions, but usually yields several fragments. Importantly, when adenocarcinoma is present at the margin, the risk of recurrence is 
a Clear lateral margins

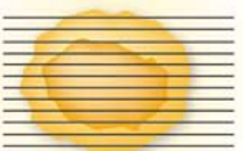

Benign Barrett's esophagus mucosa
Positive lateral margins

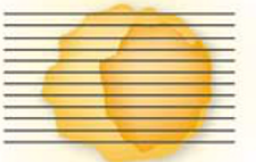

Neoplastic Barrett's esophagus
C

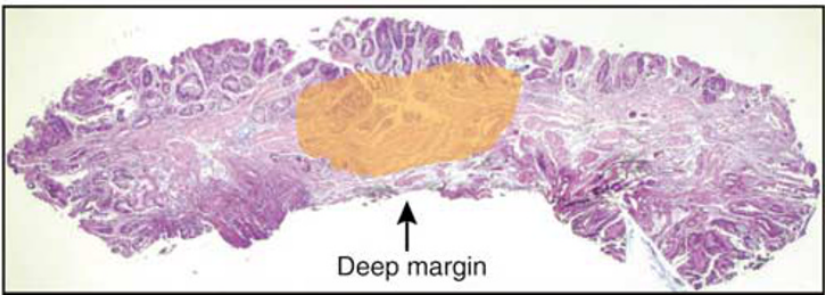

Figure 3 Evaluation of endoscopic mucosal resection: 2-mm step sections after stretching and fixation of the specimen (a and $\mathbf{b}$ ). Appropriate inking of lateral (a and b) and deep (c) margins allows optimal evaluation of the specimen.

high, as noted in $37-50 \%$ of the cases. ${ }^{15-17}$ In the setting of EMR for gastric cancer, a lateral clearance of $<2 \mathrm{~mm}$ was also associated with an increased risk of local recurrence, but similar data are not available for Barrett's esophagus-related neoplasms. ${ }^{15}$

Technical artifacts, such as hemorrhage and electrodiathermic burns can be encountered, and although they rarely limit the histologic interpretation, they may warrant being mentioned in the final report. ${ }^{18}$

In addition to the size of the specimen and the status of the margins (lateral and deep), pathologists should report on the grade of the lesion (low and HGD, intramucosal or invasive adenocarcinoma), degree of differentiation, and depth of invasion. The status of vascular invasion should be noted, especially in the cases with submucosal extension, as it might dictate changes in the patients' management. It might also be informative to rapport whether the lateral margins are composed of metaplastic or squamous epithelium.

\section{Therapeutic Efficacy of EMR}

EMR is being validated as a safe alternative to esophagectomy. A recent prospective series of 100 patients with 'low-risk' adenocarcinomas (well to moderately differentiated, $\leq 20 \mathrm{~mm}$ in diameter, and confined to the mucosa without angiolymphatic invasion or ulcer on endoscopy) reported no death and an overall recurrence rate of $11 \%$ during a mean follow-up of 36.7 months (range: 2-83 months). ${ }^{13}$ Although bleeding can be observed in up to $14 \%$ of the cases, most of it is managed endoscopically in an outpatient setting. Perforation is observed in $1.8 \%$ of

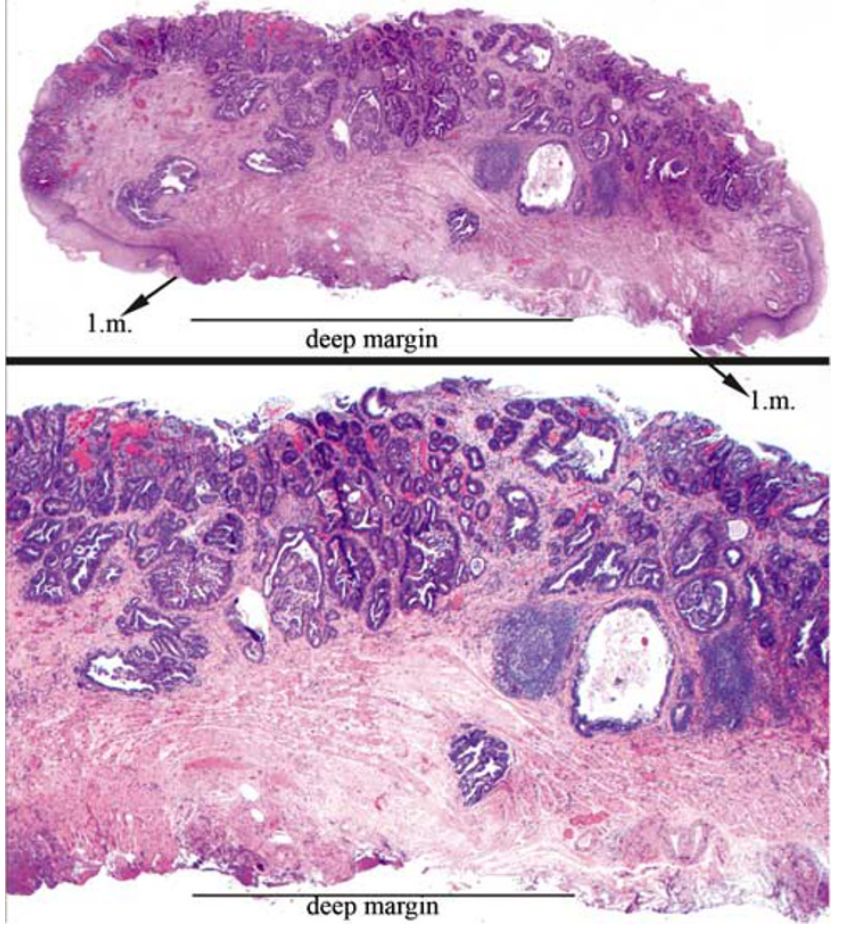

Figure 4 Superficially invasive esophageal adenocarcinoma treated by endoscopic mucosal resection. The cross-section confirms the superficially invasive, moderately differentiated tumor. In this case, the deep and lateral margins are negative.

the procedures and has been treated effectively by medical therapy, although deaths have not been reported. ${ }^{11-13,19-21}$

Despite the overall positive curative results, some series have reported disappointingly high percentages of positive margins, with figures as high as $62.5-83 \%$ of cases. ${ }^{14,22-24}$ The reasons are numerous and, likely in part, are operator dependent. However, the superiority of one resection technique vs another has not yet been evaluated fully. It has been suggested that tumor grade might be important in the failure to obtain clear margins. In one series, $88 \%$ of the high-grade, non-invasive neoplasms were resected with positive margins as opposed to $12 \%$ of low-grade neoplasms. ${ }^{24}$ Another factor may be the method of assessing margins. Various authors define completeness of resection differently. Some report the margin status only for the final EMR in patients undergoing sequential resection. ${ }^{20}$ Others define completeness of excision based on the status of post-operative biopsies of the lesional area, regardless of the margin status of the actual EMR specimen. ${ }^{25}$ The site of the positive margin is also important. In our experience, $44 \%$ of the EMRs with positive lateral/circumferential margin(s) and negative deep margin had no residual tumor and/or recurrence at the last biopsy with a median followup of 23 months. However, $86 \%$ of the EMRs with a positive deep margin had residual tumors, despite the use of photodynamic therapy in some cases. ${ }^{14}$ 
This was confirmed by Prasad et al, ${ }^{26}$ who reported that in their series of 25 patients, none with negative mucosal margins had residual tumor at subsequent esophagectomy, whereas $50 \%$ of the cases with submucosal invasive carcinoma had residual adenocarcinoma at surgery, and $30 \%$ had metastatic lymph nodes.

Follow-up biopsies carried out to ensure the absence of residual neoplasia should be evaluated with caution. In a study evaluating post-gastric EMR biopsies reactive epithelial atypia changes, including mucin depletion, clear cell degeneration, and signetring cell-like change, can be difficult to distinguish from residual neoplastic glands and should be assessed judiciously. Such a study has not been carried out in Barrett's esophagus neoplasms. ${ }^{27}$

\section{Diagnostic Utility of EMR}

Some investigators have advocated the use of EMR as a staging and diagnostic tool. ${ }^{14,20,28}$

In a 2006 study, a change in diagnosis from the original biopsies was noted in $37 \%$ of the cases, with the biopsies underreporting the neoplastic grade in $21 \%$ of the cases and overreporting it in $16 \% .^{14}$ Conio et $a 2^{29}$ also reported a diagnostic reclassification of $26 \%$ of cases based on examination of the EMR specimen. In their series of 48 patients, Larghi et al reported that on the basis of the EMRs, 6 of 25 patients with an initial diagnosis of HGD were upgraded to intramucosal carcinoma and 6 of 15 patients with a biopsy diagnosis of intramucosal carcinoma were upstaged to invasive carcinoma. ${ }^{36}$ Discrepancies between biopsies and EMRs were shown to be more common, when the lesions were large $(>10 \mathrm{~mm})$ and when less-extensive biopsy sampling was carried out. $^{30}$ These changes in grade and stage are significant, as lymph node metastases can be observed in up to $4 \%$ of intramucosal carcinoma and in up to $27 \%$ of submucosal tumors. ${ }^{18,31-34}$

\section{EMR as a Staging Modality for Early Neoplasms}

Despite significant advances, endoscopic ultrasound has only a $72-95 \%$ accuracy rate in distinguishing between mucosal (T1m) and submucosal (T1sm) disease. ${ }^{12,35}$ Overstaging by endoscopic ultrasound occurs in up to $12.5 \%$ of cases and understaging in $16-20 \%$ of the cases. ${ }^{9,12,35}$

In another series, EMRs showed submucosal invasion in $40 \%$ of patients staged as intramucosal carcinoma by endoscopic ultrasound. ${ }^{36}$ In our experience, endoscopic ultrasound correctly staged $70 \%$ of early neoplasms as intramucosal $(n=10)$ or invasive (submucosal) tumors $(n=2)$ but overstaged three lesions (T1sm for actual mucosal lesions) and understaged two (Tx for actual intramucosal neoplasms). ${ }^{14}$ We showed recently that a large vertical dimension of the neoplasm and duplication of muscularis mucosa were commonly associated with overstaging by endoscopic ultrasound. ${ }^{37}$

\section{EMR Helps in Assessing the Risk of Lymph Node Metastasis}

The evaluation of well-oriented EMRs allows measurement of the depth of invasion. It is an important piece of information, as a submucosal infiltration of $500 \mathrm{im}$ represents the quantitative cutoff for an increased risk of lymph node metastasis. ${ }^{38}$ The risk for submucosal cancer is $20-25 \% .^{4,39}$

Yet the assessment of the risk of metastasis may be modified radically, when the implications of the

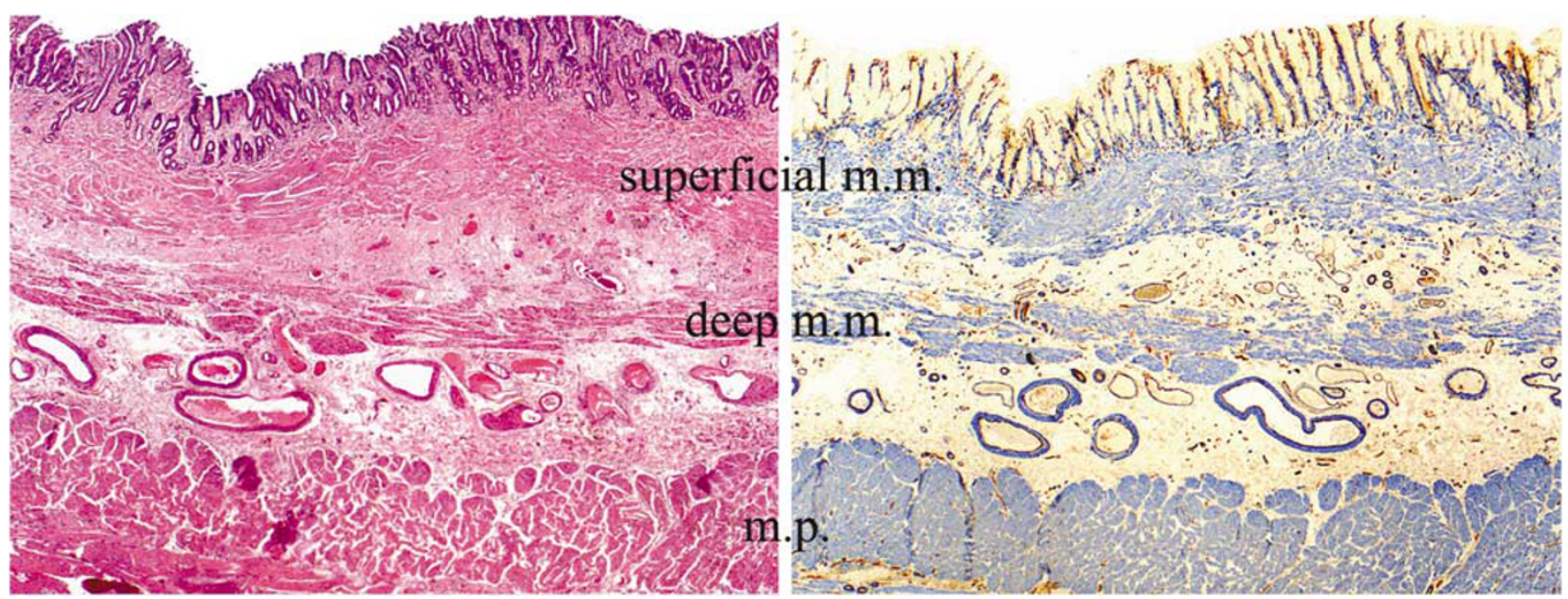

Figure 5 Duplicated muscularis mucosa. Both images show this (H\&E, left, and cocktail CD31/SMA immunohistochemistry, right). This architectural anomaly has been implicated in the inadequate staging of endoscopic ultrasound. The differential risk of metastasis between deep and superficial submucosal layers is yet to be determined. m.m., muscularis mucosa; m.p., muscularis propria. 
duplication of muscularis mucosae seen in Barrett's esophagus are appreciated fully. ${ }^{40}$ Indeed, taking prominent outer muscularis mucosa to be muscularis propria is a common mistake that critically impacts the evaluation of the risk of lymphatic metastasis (Figure 5).

\section{EMR Improves Diagnostic Consistency}

Variation in the evaluation of Barrett's esophagusassociated dysplasia is a vexing problem for surgical pathologists, with a interobserver $\kappa$-value of only 0.50 ( $\sim 75 \%$ of interobserver concordance).$^{41}$ The reasons for discrepancy between pathologists are multiple, including the experience of the observers, the size of the sampled specimen, the quality of material, and the quality of slide preparation. We have reported recently that interobserver agreement of Barrett's esophagus-related neoplasia on EMRs is significantly higher than on pre-EMR biopsy specimens. ${ }^{42}$ It likely relates to the larger tissue sampling compared with that of biopsies and the ability to evaluate mucosal landmarks, such as double muscularis mucosae. In our series, none of the 25 biopsies had $100 \%$ interobserver agreement among all reviewers, whereas 13 cases (52\%) were given diagnoses that differed by only one grade and $36 \%$ of the cases $(n=9)$ that differed by two grades. Diagnoses spanning four different grades were recorded in $12 \%$ of the cases. Alternatively, of the 25 corresponding EMRs, all reviewers gave the same diagnosis in $16 \%$ of the cases, including three intramucosal carcinomas and one invasive adenocarcinoma. Thirteen cases were given diagnoses that differed by only one grade. Overall, $24 \%$ of the cases had a diagnostic spread of three grades, but a diagnosis spanning four grades was recorded in only one EMR $(4 \%)$.

In conclusion, although the validity of EMR as a definitive therapeutic tool continues to be confirmed for well-selected patients, it has already proven to be a staging procedure complementary to endoscopic ultrasound for early lesions and also to enhance diagnostic reproducibility between pathologists.

\section{Photodynamic therapy}

PDT is the most extensively studied ablative method for superficial neoplasias arising in Barrett's esophagus. In PDT, an inactive photosensitizing drug is administered to the patient. It then accumulates within the epithelium and, after that, it is activated by an endoscopically delivered light of an appropriate wavelength. As the drug absorbs the light energy, the latter is transferred to oxygen molecules. The photoreaction results in generation of highenergy cytotoxic singlet oxygen molecules that damage the tissue (Figure 6). ${ }^{43}$

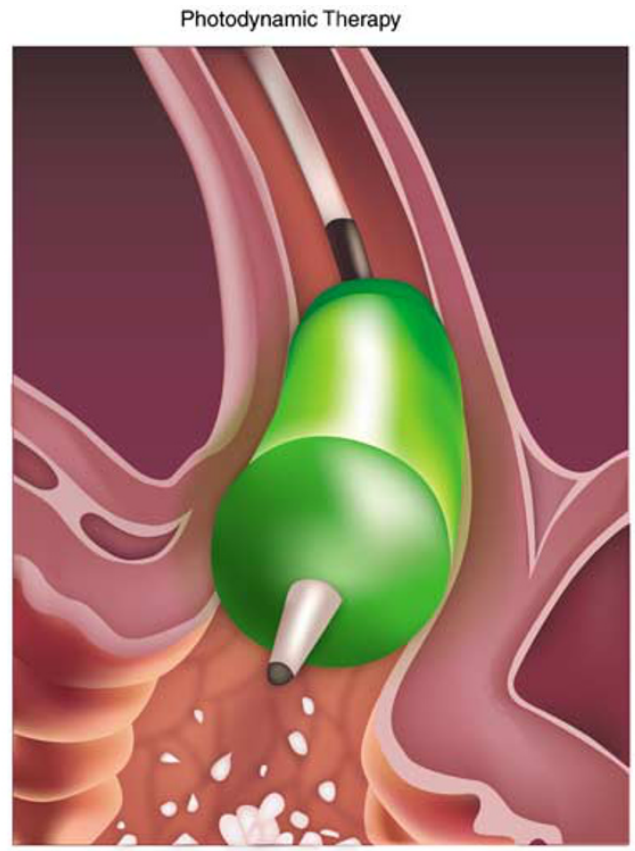

b

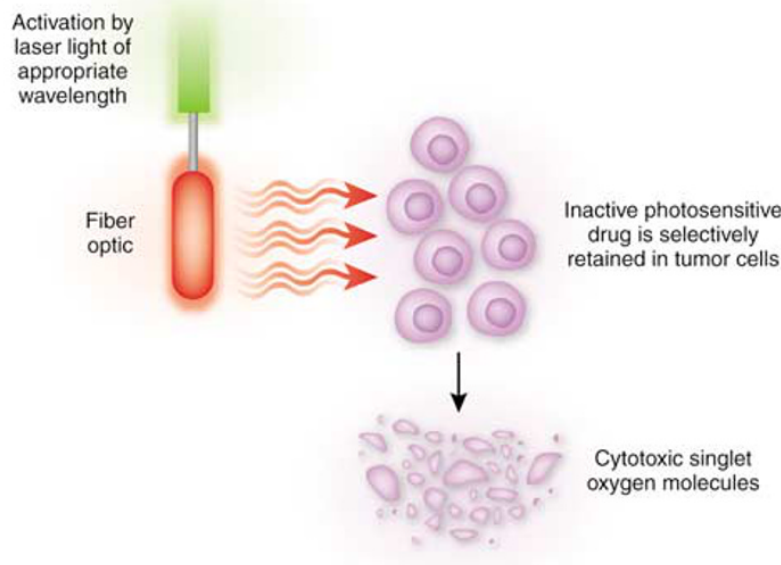

Figure 6 Principal of photodynamic therapy. (a) After injection/ intake of a photosensitizing agent which accumulates preferentially into the neoplastic epithelium, light of appropriate wavelength is delivered endoscopically. (b) Upon the light delivery, cytotoxic singlet oxygen molecules are generated and destroy the neoplastic cells.

Two photosensitizing agents have been evaluated in clinical studies of Barrett's esophagus: 5-aminolevulinic acid (5-ALA) and porfimer sodium (Photofrin $\AA$, Axcan Pharma, Inc.). No comparative studies of these agents to date have been noted.

The advantages of 5-ALA include oral administration, rapid onset of photosensitivity (4-6h), and limited duration of photosensitivity (days). The depth of mucosal destruction is more superficial than with that of porfimer sodium. Porfimer sodium is the only approved photosensitizer for use in esophageal PDT in the United States. Unlike 5-ALA, porfimer sodium is administered intravenously. 
494

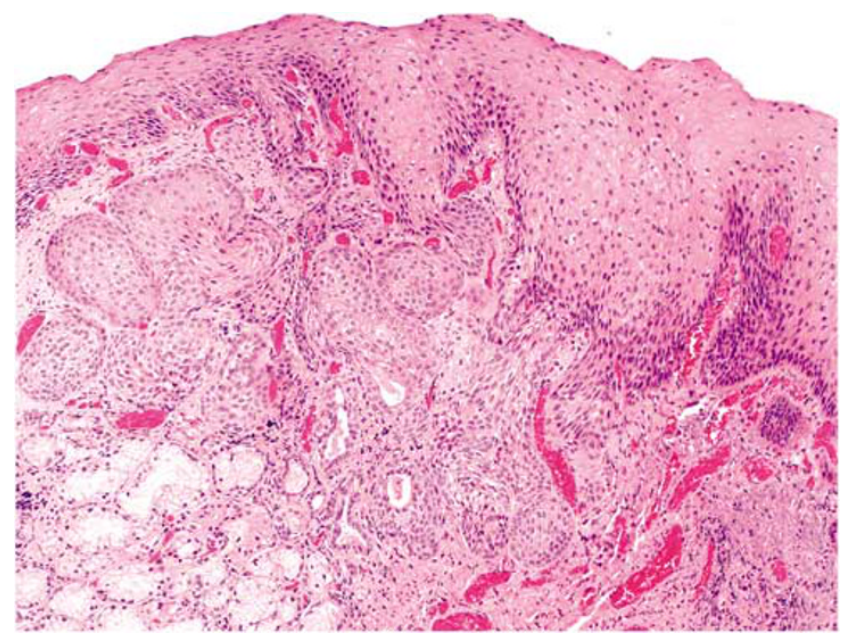

Figure 7 Neosquamous epithelium post-PDT. The restored squamous epithelium grows along (and replaces) Barrett's glands and ducts of mucous glands.

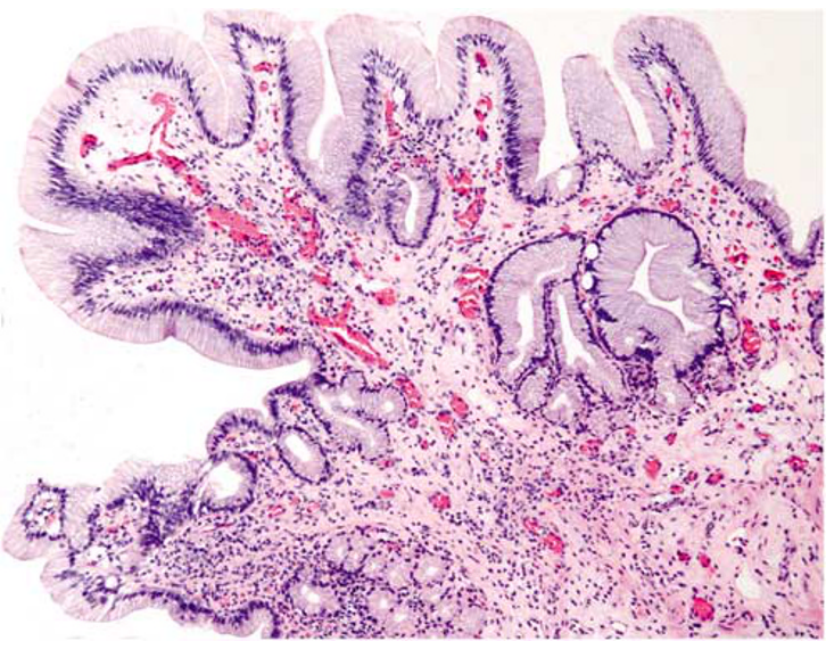

Figure 8 Despite PDT and proton pump inhibitor, residual nondysplastic columnar epithelium can be seen. In this case, there are no residual goblet cells. The inflammation is minimal. The stroma is expanded and fibrotic.

Forty-eight hours later, light (at $630 \mathrm{~nm}$ ) is delivered endoscopically. One treatment may be composed of two sessions, if the mucosal destruction is inadequate at a $48 \mathrm{~h}$ repeat endoscopy.

PDT is associated with a good clinical response, with dysplasia and/or superficial adenocarcinoma disappearing in $67-100 \%$ of the cases. ${ }^{44-51}$ A recent 5-year follow-up study showed an overall eradication of HGD of $77 \%$ compared with $39 \%$ of omeprazole alone, as well as a decreased risk of metachronous adenocarcinomas. ${ }^{44}$ Accurate histologic grading of pre-therapeutic material is important, as it has been shown repeatedly that the higher the histologic grade, the lesser the response rate. ${ }^{10}$ Mucosal/submucosal invasive adenocarcinomas (pT1) are less likely to be treated successfully when

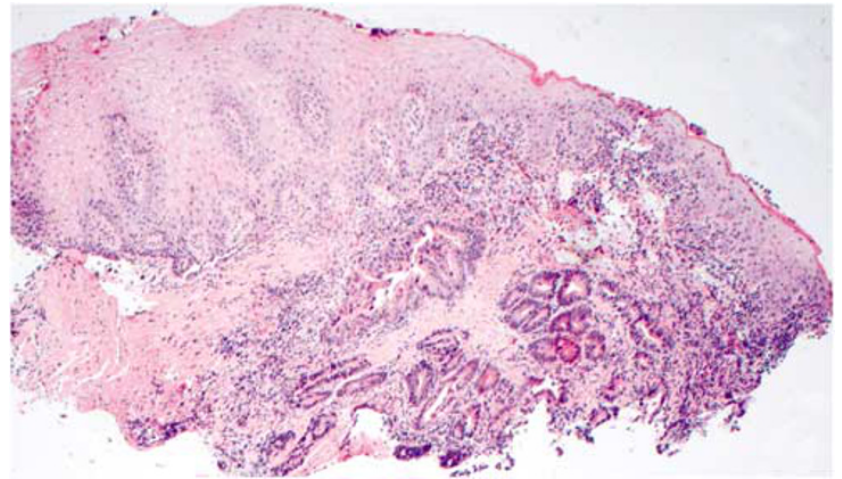

Figure 9 Example of neoplastic malignant Barrett's esophagus buried under restored squamous mucosa. Endoscopic ultrasound and additional biopsies may be necessary to rule out an invasive adenocarcinoma. This common complication makes surveillance difficult, and forces the gastroenterologist to take multiple biopsies even in an area of endoscopically normal squamous mucosa.

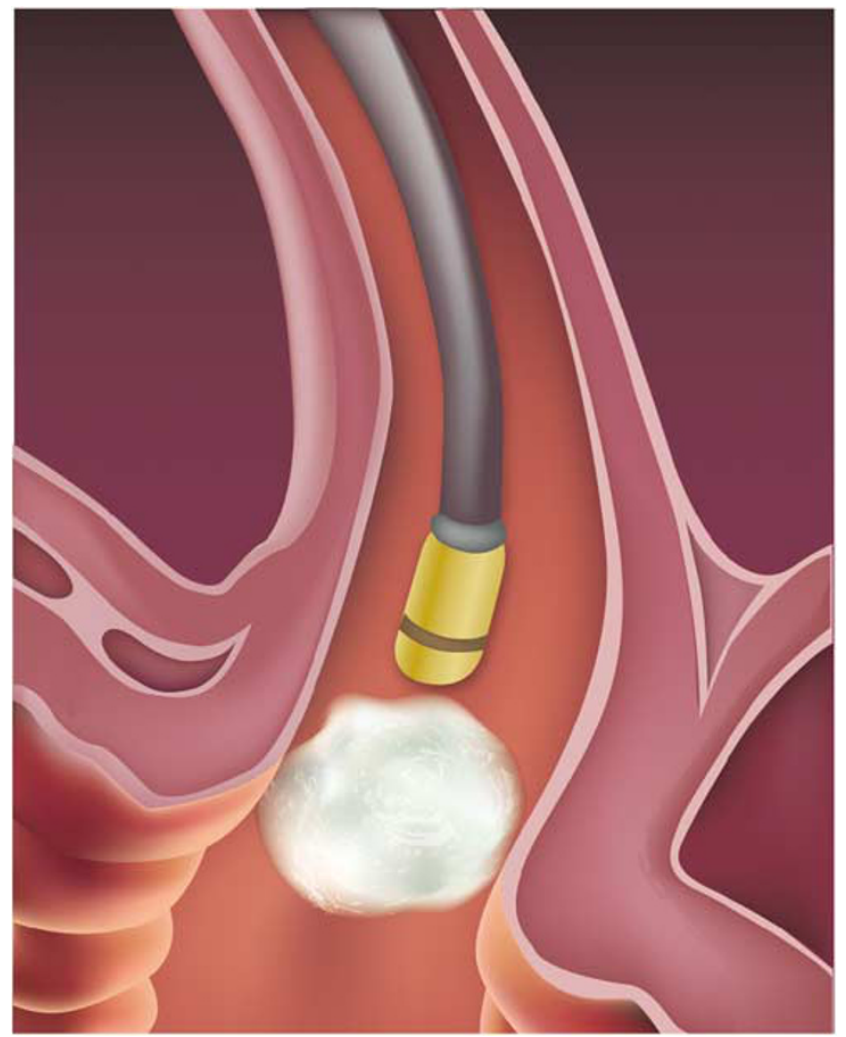

Figure 10 Cryotherapy for dysplastic Barrett's esophagus. Liquid nitrogen is sprayed directly onto the mucosa, which is destroyed by freezing. The spray can be applied several times.

compared with HGD. For instance, some authors have reported no evidence of recurrence in only $25 \%$ of pT1b/limited pT2 tumors (with limited follow-up). ${ }^{52,53}$ In contrast, the success rates for HGD and intramucosal carcinoma are 90 and $82.1 \%$, respectively, and the progression of HGD or intramucosal carcinoma to invasive cancer is low, varying from 4 to $13 \% .{ }^{44,53}$ Importantly, $92 \%$ of the 
cases with an re-emergence of neoplasia after initial eradication arise at the original site, reflecting the persistence of genetic abnormalities. ${ }^{53}$ Therefore, in most series, PDT is combined with other ablative methods (particularly EMR), a strategy necessary for achieving significant success.

\section{Benign Histologic Changes After PDT}

Squamous re-epithelialization is common after acid suppression and anti-reflux surgery, ${ }^{10,54}$ as well as after electrocoagulation, argon plasma coagulation, ${ }^{55}$ and laser. ${ }^{54,56}$ In a series of 33 patients, the authors showed that the percentage of biopsies with squamous islands of re-epithelialization changes from $36.7 \%$ before PDT to $77.5 \%$ after (Figure 7 ). ${ }^{10}$ Usually, no atypia is seen in the restored squamous epithelium. Post-PDT, goblet cells are usually significantly decreased. Stromal capillary proliferation and eosinophilia are also noted early after PDT, although fibromuscular proliferation might be prominent at 6 months and is usually associated with glandular atrophy. (Figure 8) Reactive atypia of the columnar epithelium is more prominent post-PDT than pre-PDT, but is usually mild and not diagnostically challenging. ${ }^{57}$ Esophageal stricture requiring dilatation is reported variably $(6.25-29 \%) .^{52,53}$

Other common side effects of PDT include nausea, vomiting, chest pain, odynophagia, and skin photosensitivity. Skin fragility, solar dermatitis, and severe burn with blistering are rare. Complications associated with 5-ALA are less common and milder, but hypotension and tachyarrhythmias have been reported. ${ }^{58}$

\section{The Histopathology of Persistent Neoplasia After PDT}

In most cases, the histologic grade of persistent neoplasia is unchanged after PDT. Less commonly, it is downgraded. ${ }^{10}$ Distally located lesions are more likely to persist after PDT ( $4 \%$ of proximal lesions vs $15.3 \%) .{ }^{10,53,59}$ The reason is unclear; however, as the distal esophagus is exposed to high concentrations of gastric acid (or bile), it is plausible that the COX-2 overexpression is evoked, in turn promoting the persistence of neoplastic tissue. ${ }^{60-62}$

Diffuse and multifocal neoplastic disease is also prone to persist after PDT. ${ }^{10,59}$ We noted recently that all patients who responded to a single PDT course (with or without additional fulguration) had a short segment of neoplasia $(<4 \mathrm{~cm})$, whereas twothirds of patients with neoplasia spanning $\geq 4 \mathrm{~cm}$ needed more than one course of treatment (repeated PDT with fulguration).

\section{Post-PDT Buried Barrett's Epithelium and Neoplasia}

After PDT, Barrett's esophagus mucosa concealed by restored squamous epithelium (buried Barrett's esophagus) is reported in $0-40 \%^{7,45,47-49,63-65}$ and buried neoplasms in $0-3.7 \%$ of patients (Figure 9). ${ }^{7,45,48,49}$ A concern associated with buried Barrett's esophagus is the risk of unnoticed malignant transformation..$^{54,66,67}$

In our experience, completely buried Barrett's esophagus (absent before PDT) was observed in $17.3 \%$ of patients after treatment. More importantly, completely buried neoplasms, observed in $1.9 \%$ of 52 patients before treatment, increased to $25.0 \%$ of patients after PDT. Importantly, $7.4 \%$ of the residual neoplasms were concealed completely by the squamous epithelium, and in most cases, these represented the highest grade and usually the sole residual neoplastic focus. ${ }^{53,68}$ Although patients with buried neoplasms respond to treatment similar to those with only surface neoplasms, the detection of buried neoplasms can be difficult, and thorough endoscopic surveillance with deep, extensive biopsies is cardinal.

\section{Other Ablative Therapies}

There has been a recent surge in the introduction of new endoscopic techniques seeking to complement some of the main shortcomings of PDT, including equipment cost and availability, technical expertise required, incomplete ablation efficacy, and post-procedure photosensitivity and stricturing.

Recently, we have seen the introduction of radiofrequency ablation (RFA) catheters used for the ablation of Barrett's esophagus and various grades of dysplasia (BARRx Medical, Sunnyvale, CA). Studies have suggested that the combined use of the balloonbased circumferential RFA catheter ( Halo $^{360}$ (R) and focal RFA catheter (Halo ${ }^{90}($ ) ) results in high rates of Barrett's esophagus mucosa ablation $(98 \%$ at 2 years of follow-up) with only a few complications. ${ }^{69}$ Preliminary data on the eradication of dysplastic Barrett's esophagus (low and HGD) show efficacy in $90-100 \%$ at short term follow-up (6 months). ${ }^{70,71}$ Multicenter studies for further defining the role of this technology in dysplastic Barrett's esophagus are in progress.

A cryospray technique has also been introduced as an ablative technique. The cryoablation technique involves the use of liquid nitrogen (at $-196^{\circ} \mathrm{C}$ ) delivered to the Barrett's esophagus mucosa under direct endoscopic vision using a low-pressure spray catheter. (Figure 10) A pilot study of 11 patients published in 2005 showed histologic and endoscopic regressions of Barrett's esophagus in $78 \%$, including one patient with HGD. ${ }^{72}$ However, buried Barrett's esophagus glands were found in $18 \%$ of patients at 1 month follow-up sampling. Furthermore, chest pain and dysphagia have been reported post-procedure in up to $45 \%$, particularly in those who receive circumferential ablation. ${ }^{72}$ Additional studies of cryoablation are in progress. 


\section{Conclusions}

Although EMR is quietly revolutionizing the diagnosis and treatment of early neoplasia in Barrett's esophagus, the specific role of the various ablative techniques in clinical practice remains uncertain. To date, PDT is the only FDA-approved treatment for HGD arising in Barrett's esophagus. The combination of these new ablative technologies with EMR will likely provide value in a subset of patients, namely those with nodular dysplasia or intramucosal carcinoma. $^{73}$ Whether evaluating EMRs or diagnosing post-ablation follow-up biopsies, the histopathologic interpretation, and thus the role of pathologists, will be crucial in validating this expanding new therapeutic armamentarium.

\section{References}

1 Reed MF, Tolis Jr G, Edil BH, et al. Surgical treatment of esophageal high-grade dysplasia. Ann Thorac Surg 2005;79:1110-1115; discussion-5.

2 Holscher AH, Bollschweiler E, Schroder W, et al. Prognostic differences between early squamous-cell and adenocarcinoma of the esophagus. Dis Esophagus 1997;10:179-184.

3 Birkmeyer JD, Siewers AE, Finlayson EV, et al. Hospital volume and surgical mortality in the United States. N Engl J Med 2002;346:1128-1137.

4 Stein HJ, Feith M, Mueller J, et al. Limited resection for early adenocarcinoma in Barrett's esophagus. Ann Surg 2000;232:733-742.

5 Nigro JJ, Hagen JA, DeMeester TR, et al. Prevalence and location of nodal metastases in distal esophageal adenocarcinoma confined to the wall: implications for therapy. J Thorac Cardiovasc Surg 1999;117:16-23; discussion-5.

6 Rice TW, Zuccaro Jr G, Adelstein DJ, et al. Esophageal carcinoma: depth of tumor invasion is predictive of regional lymph node status. Ann Thorac Surg 1998;65:787-792.

7 Overholt BF, Panjehpour M, Halberg DL. Photodynamic therapy for Barrett's esophagus with dysplasia and/or early stage carcinoma: long-term results. Gastrointest Endosc 2003;58:183-188.

8 Attwood SE, Lewis CJ, Caplin S, et al. Argon beam plasma coagulation as therapy for high-grade dysplasia in Barrett's esophagus. Clin Gastroenterol Hepatol 2003;1:258-263.

9 Ell C, May A, Gossner L, et al. Endoscopic mucosal resection of early cancer and high-grade dysplasia in Barrett's esophagus. Gastroenterology 2000;118: 670-677.

10 Ban S, Mino M, Nishioka NS, et al. Histopathologic aspects of photodynamic therapy for dysplasia and early adenocarcinoma arising in Barrett's esophagus. Am J Surg Pathol 2004;28:1466-1473.

11 May A, Gossner L, Behrens A, et al. A prospective randomized trial of two different endoscopic resection techniques for early stage cancer of the esophagus. Gastrointest Endosc 2003;58:167-175.

12 Nijhawan PK, Wang KK. Endoscopic mucosal resection for lesions with endoscopic features suggestive of malignancy and high-grade dysplasia within Barrett's esophagus. Gastrointest Endosc 2000;52:328-332.

13 Ell C, May A, Pech O, et al. Curative endoscopic resection of early esophageal adenocarcinomas (Barrett's cancer). Gastrointest Endosc 2007;65:3-10.

14 Mino-Kenudson M, Brugge WR, Puricelli WP, et al. Management of superficial Barrett's epithelium-related neoplasms by endoscopic mucosal resection: clinicopathologic analysis of 27 cases. Am J Surg Pathol 2005;29:680-686.

15 Hamada T, Kondo K, Itagaki Y, et al. Endoscopic mucosal resection for early gastric cancer. Nippon Rinsho 1996;54:1292-1297.

16 Ono H, Kondo H, Gotoda T, et al. Endoscopic mucosal resection for treatment of early gastric cancer. Gut 2001;48:225-229.

17 Mizumoto S, Misumi A, Harada K, et al. Evaluation of endoscopic mucosal resection (EMR) as a curative therapy against early gastric cancer. Nippon Geka Gakkai Zasshi 1992;93:1071-1074.

18 Rice TW, Blackstone EH, Goldblum JR, et al. Superficial adenocarcinoma of the esophagus. J Thorac Cardiovasc Surg 2001;122:1077-1090.

19 Takeshita K, Tani M, Inoue H, et al. Endoscopic treatment of early oesophageal or gastric cancer. Gut 1997; 40:123-127.

20 Ahmad NA, Kochman ML, Long WB, et al. Efficacy, safety, and clinical outcomes of endoscopic mucosal resection: a study of 101 cases. Gastrointest Endosc 2002;55:390-396.

21 Giovannini M, Bernardini D, Moutardier V, et al. Endoscopic mucosal resection (EMR): results and prognostic factors in 21 patients. Endoscopy 1999; 31:698-701.

22 Vieth M, Ell C, Gossner L, et al. Histological analysis of endoscopic resection specimens from 326 patients with Barrett's esophagus and early neoplasia. Endoscopy 2004;36:776-781.

23 Ponchon T, Ciorirlan M, Saurin J-C. Endoscopic mucosal resection for superficial esophageal neoplastic lesion; comparison between macroscopic, histological, and follow-up results. Gastrointest Endosc 2004; 59:AB253 (W1549)

24 Lewis J, Lutzke L, Smyrk T. The limitations of endoscopic mucosal resection in Barrett's esophagus. Gastrointest Endosc 2004;59:AB101 (Abstract 401).

25 Pacifico RJ, Wang KK, Wongkeesong LM, et al. Combined endoscopic mucosal resection and photodynamic therapy versus esophagectomy for management of early adenocarcinoma in Barrett's esophagus. Clin Gastroenterol Hepatol 2003;1:252-257.

26 Prasad GA, Buttar NS, Wongkeesong LM, et al. Significance of neoplastic involvement of margins obtained by endoscopic mucosal resection in Barrett's esophagus. Am J Gastroenterol 2007;102:2380-2386.

27 Mitsuhashi T, Lauwers GY, Ban S, et al. Post-gastric endoscopic mucosal resection surveillance biopsies: evaluation of mucosal changes and recognition of potential mimics of residual adenocarcinoma. Am J Surg Pathol 2006;30:650-656.

28 Lauwers GY, Ban S, Mino M, et al. Endoscopic mucosal resection for gastric epithelial neoplasms: a study of 39 cases with emphasis on the evaluation of specimens and recommendations for optimal pathologic analysis. Mod Pathol 2004;17:2-8.

29 Conio M, Repici A, Cestari R, et al. Endoscopic mucosal resection for high-grade dysplasia and intra- 
mucosal carcinoma occurring in Barrett's esophagus. Gastrointest Endosc 2004;59:AB253.

30 Hull MJ, Mino-Kenudson M, Nishioka NS, et al. Endoscopic mucosal resection: an improved diagnostic procedure for early gastroesophageal epithelial neoplasms. Am J Surg Pathol 2006;30:114-118.

31 Liu L, Hofstetter WL, Rashid A, et al. Significance of the depth of tumor invasion and lymph node metastasis in superficially invasive (T1) esophageal adenocarcinoma. Am J Surg Pathol 2005;29: 1079-1085.

32 Stein HJ, Feith M, Bruecher BL, et al. Early esophageal cancer: pattern of lymphatic spread and prognostic factors for long-term survival after surgical resection. Ann Surg 2005;242:566-573; discussion 73-5.

33 Westerterp M, Koppert LB, Buskens CJ, et al. Outcome of surgical treatment for early adenocarcinoma of the esophagus or gastro-esophageal junction. Virchows Arch 2005;446:497-504.

34 Oh DS, Hagen JA, Chandrasoma PT, et al. Clinical biology and surgical therapy of intramucosal adenocarcinoma of the esophagus. J Am Coll Surg 2006;203:152-161.

35 Scotiniotis IA, Kochman ML, Lewis JD, et al. Accuracy of EUS in the evaluation of Barrett's esophagus and high-grade dysplasia or intramucosal carcinoma. Gastrointest Endosc 2001;54:689-696.

36 Larghi A, Lightdale CJ, Memeo L, et al. EUS followed by EMR for staging of high-grade dysplasia and early cancer in Barrett's esophagus. Gastrointest Endosc 2005;62:16-23.

37 Mandal RV, Forcione DG, Brugge WR, et al. Effect of tumor characteristics and duplication of the muscularis mucosae on the endoscopic staging of superficial Barrett esophagus-related neoplasia. Am J Surg Pathol; 26 November 2008 [e-pub ahead of print].

38 Participants in the Paris Workshop. The Paris endoscopic classification of superficial neoplastic lesions: esophagus, stomach, and colon: November 30 to December 1, 2002. Gastrointest Endosc 2003;58:S3-43.

39 Nigro JJ, Hagen JA, DeMeester TR, et al. Prevalence and location of nodal metastases in distal esophageal adenocarcinoma confined to the wall: implications for therapy. J Thorac Cardiovasc Surg 1999;117:16-23; discussion-5.

40 Lewis JT, Wang KK, Abraham SC. Muscularis mucosae duplication and the musculo-fibrous anomaly in endoscopic mucosal resections for Barrett esophagus: implications for staging of adenocarcinoma. Am J Surg Pathol 2008;32:566-571.

41 Montgomery E, Bronner MP, Goldblum JR, et al. Reproducibility of the diagnosis of dysplasia in Barrett esophagus: a reaffirmation. Hum Pathol 2001;32:368-378.

42 Mino-Kenudson M, Hull MJ, Brown I, et al. Endoscopic mucosal resection as a diagnostic modality: interrater diagnostic correlation for endoscopic mucosal resection specimens is better than biopsy specimens. Gastroenterology 2006;130:A410.

43 Pass HI. Photodynamic therapy in oncology: mechanisms and clinical use. J Natl Cancer Inst 1993;85: 443-456.

44 Overholt BF, Lightdale CJ, Wang KK, et al. Photodynamic therapy with porfimer sodium for ablation of high-grade dysplasia in Barrett's esophagus: international, partially blinded, randomized phase III trial. Gastrointest Endosc 2005;62:488-498.
45 Wolfsen HC, Woodward TA, Raimondo M. Photodynamic therapy for dysplastic Barrett esophagus and early esophageal adenocarcinoma. Mayo Clin Proc 2002;77:1176-1181.

46 Wang KK. Current status of photodynamic therapy of Barrett's esophagus. Gastrointest Endosc 1999;49: S20-S23.

47 Wang KK, Sampliner RE. Mucosal ablation therapy of Barrett esophagus. Mayo Clin Proc 2001;76: 433-437.

48 Overholt BF, Panjehpour M, Haydek JM. Photodynamic therapy for Barrett's esophagus: follow-up in 100 patients. Gastrointest Endosc 1999;49:1-7.

49 Gossner L, Stolte M, Sroka R, et al. Photodynamic ablation of high-grade dysplasia and early cancer in Barrett's esophagus by means of 5-aminolevulinic acid. Gastroenterology 1998;114:448-455.

50 Ackroyd R, Brown NJ, Davis MF, et al. Photodynamic therapy for dysplastic Barrett's oesophagus: a prospective, double blind, randomised, placebo controlled trial. Gut 2000;47:612-617.

51 Pech O, Gossner L, May A, et al. Long-term results of photodynamic therapy with 5-aminolevulinic acid for superficial Barrett's cancer and high-grade intraepithelial neoplasia. Gastrointest Endosc 2005;62:24-30.

52 Foroulis CN, Thorpe JA. Photodynamic therapy (PDT) in Barrett's esophagus with dysplasia or early cancer. Eur J Cardiothorac Surg 2006;29:30-34.

53 Lauwers GY, personal data.

54 Biddlestone LR, Barham CP, Wilkinson SP, et al. The histopathology of treated Barrett's esophagus: squamous reepithelialization after acid suppression and laser and photodynamic therapy. Am J Surg Pathol 1998;22:239-245.

55 Van Laethem JL, Cremer M, Peny MO, et al. Eradication of Barrett's mucosa with argon plasma coagulation and acid suppression: immediate and mid term results. Gut 1998;43:747-751.

56 Barham CP, Jones RL, Biddlestone LR, et al. Photothermal laser ablation of Barrett's oesophagus: endoscopic and histological evidence of squamous reepithelialisation. Gut 1997;41:281-284.

57 Mino-Kenudson M, Lauwers GY. Pathology of Barrett's esophagus after photodynamic therapy. Mod Pathol 2007;20:A550.

58 Peters F, Kara M, Rosmolen W, et al. Poor results of 5-aminolevulinic acid-photodynamic therapy for residual high-grade dysplasia and early cancer in Barrett esophagus after endoscopic resection. Endoscopy 2005;37:418-424.

59 Mino-Kenudson M, Ohana M, Ban S, et al. Barrett esophagus associated neoplasms treated by photodynamic therapy: determination of limiting factors (Abstract 517). Lab Invest 2006;86:114A.

60 Shirvani VN, Ouatu-Lascar R, Kaur BS, et al. Cyclooxygenase 2 expression in Barrett's esophagus and adenocarcinoma: ex vivo induction by bile salts and acid exposure. Gastroenterology 2000;118: 487-496.

61 Hamoui N, Peters JH, Schneider S, et al. Increased acid exposure in patients with gastroesophageal reflux disease influences cyclooxygenase-2 gene expression in the squamous epithelium of the lower esophagus. Arch Surg 2004;139:712-716; discussion 6-7.

62 Paulson TG, Reid BJ. Focus on Barrett's esophagus and esophageal adenocarcinoma. Cancer Cell 2004;6: 11-16. 
63 Wolfsen HC, Hemminger LL, Wallace MB, et al. Clinical experience of patients undergoing photodynamic therapy for Barrett's dysplasia or cancer. Aliment Pharmacol Ther 2004;20:1125-1131.

64 Barr H, Shepherd NA, Dix A, et al. Eradication of high-grade dysplasia in columnar-lined (Barrett's) oesophagus by photodynamic therapy with endogenously generated protoporphyrin IX. Lancet 1996; 348:584-585.

65 Ackroyd R, Kelty CJ, Brown NJ, et al. Eradication of dysplastic Barrett's oesophagus using photodynamic therapy: long-term follow-up. Endoscopy 2003;35:496-501.

66 Van Laethem JL, Peny MO, Salmon I, et al. Intramucosal adenocarcinoma arising under squamous re-epithelialisation of Barrett's oesophagus. Gut 2000; 46:574-577.

67 Sharma P. Recent advances in Barrett's esophagus: short-segment Barrett's esophagus and cardia intestinal metaplasia. Semin Gastrointest Dis 1999;10:93-102.

68 Mino-Kenudson M, Ban S, Ohana M, et al. Buried dysplasia and early adenocarcinoma arising in Bar- rett's esophagus after porfimer-photodynamic therapy. Am J Surg Pathol 2007;31:403-409.

69 Sharma VK, Wang KK, Overholt BF, et al. Balloonbased, circumferential, endoscopic radiofrequency ablation of Barrett's esophagus: 1-year follow-up of 100 patients. Gastrointest Endosc 2007;65:185-195.

70 Ganz RA, Overholt BF, Sharma VK, et al. Circumferential ablation of Barrett's esophagus that contains high-grade dysplasia: a US Multicenter Registry. Gastrointest Endosc 2008;68:35-40.

71 Sharma VK, Kim HJ, Musil D, et al. Circumferential ablation of Barrett esophagus with low grade dysplasia: one and two year follow-up of the AIM-LGD trial. Gastrointest Endosc 2007;65:AB155.

72 Johnston MH, Cash BD, Horwhat JD, et al. Cryoablation of Barrett's esophagus. Gastroenterology 2006;130:A640.

73 Pouw RE, Gondrie JJ, Sondermeijer C, et al. Novel combined modality therapy for Barrett's esophagus containing high-grade dysplasia: endoscopic mucosal resection followed by circumferential and focal ablation using the HALO system. Gastrointest Endosc 2007;65:AB111. 